\title{
DISPERSION OF CLUSTERS OF NANOSCALE SILICA PARTICLES USING BATCH ROTOR-STATORS
}

\author{
Shah Waez Kamaly \\ Alan Tarleton \\ Nerime Gül Özcan-Taşkın \\ Loughborough University, Department of Chemical Engineering,
}

Loughborough LE11 $3 T U$ Leicestershire, UK

\begin{abstract}
Nanoparticle powders added into a liquid medium form structures which are much larger than the primary particle size (aggregates and agglomerates)- typically of the order of 10's of microns. An important process step is therefore the deagglomeration of these clusters to achieve as fine a dispersion as possible. This paper reports the findings of a study on the dispersion of hydrophilic fumed silica nanoparticle clusters, Aerosil $200 \mathrm{~V}$, in water using two batch rotor-stators: MICCRA D-9 and VMI. The MICCRA D9 head consists of a set of teeth for the stator and another for the rotor, whereas the VMI has a stator with slots and a rotor which consists of a 4-bladed impeller attached to an outer set of teeth. The dispersion process, studied at different power input values and over a range of concentrations $(1,5,10 \mathrm{wt} . \%)$, was monitored through the evolution of PSD. Erosion was found to be the dominant breakage mechanism irrespective of operating conditions or rotor-stator type. The smallest attainable size was also found to be independent of the power input or the design of the rotor-stator. Break up kinetics increased upon the increase of power input, and this also depended on the rotor-stator design. With MICCRA D-9 which has smaller openings on both the stator and rotor, the break up rate was faster. Increasing the particle concentration decreased break up kinetics. It could also be shown that operating at high concentrations can still be
\end{abstract}


beneficial as the break up rate is higher when assessed on the basis of specific power input per mass of solids.

Key words: Nanoparticle dispersion, breakup, fragmentation, deagglomeration, silica, Aerosil 200V, agglomerates, rotor-stator

\section{INTRODUCTION}

The incorporation of nanoparticles in the formulation of a wide range of products varying from pharmaceuticals, coatings, paints, lubricants to nutraceuticals, textiles has seen a rapid increase over the past two decades resulting in not only the improvement of conventional products but also allowing products to be brought to market with properties and performance that could not be achieved previously. Dry nanoparticle powders exist in a hierarchy of structures which may include primary particles but most often agglomerates and aggregates. Whilst agglomerates can be broken up to much finer structures, aggregates cannot be disintegrated further due to the strong bonds holding them together. Therefore, once the particles are incorporated into the liquid, the main objective of the process is to deagglomerate the large structures to generate as fine a dispersion as possible. 


$$
\begin{array}{cccccc}
0 & 0 & 0 & 0 & 0 \\
0 & 0 & 0 & 0 & 0 & 0 \\
0 & 0 & 0 & 0 & 0 & 0 \\
0 & 0 & 0 & 0 & 0 & 0 \\
0 & 0 & 0 & 0 & 0 \\
0 & 0 & 0 & 0 & 0
\end{array}
$$

Primary Particles

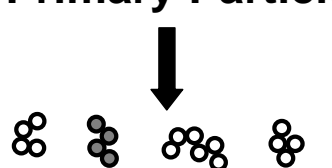

\& \& \& 80

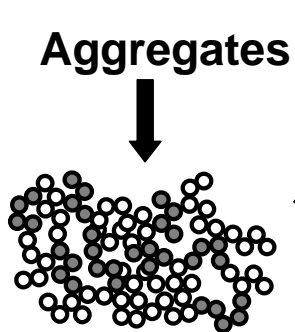

Agglomerates

Figure 1. Schematic representation of different breakup modes

(Özcan-Taşkın et al., 2009)
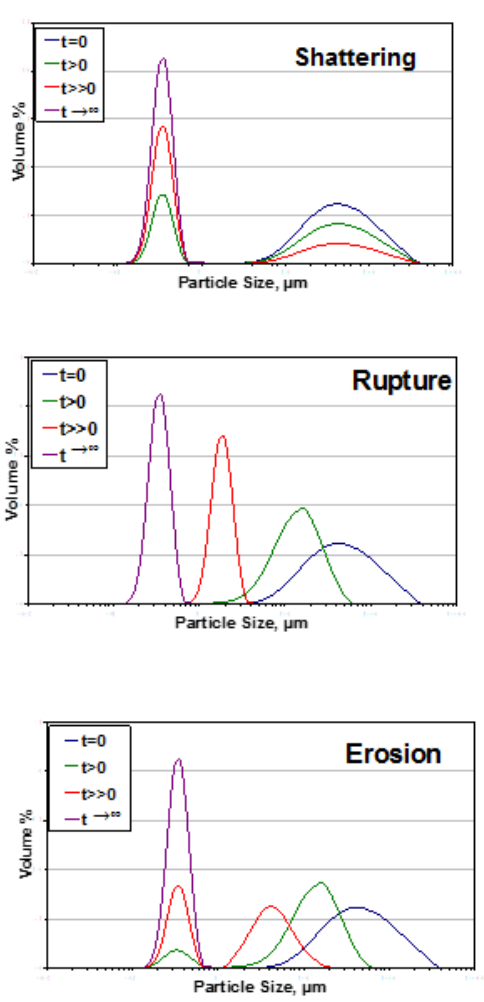

Figure 2. PSDs resulting from breakup of nanoparticle clusters through erosion, rupture and shattering (Özcan-Taşkın et al., 2009) 
Provided that the stresses present in a processing environment are sufficiently high to overcome the inter-particle bonds that hold the agglomerates together, break up can occur through different mechanisms as schematically shown in Figure 1 (Özcan-Taşkın et al., 2009). Erosion and shattering give bi-modal Particle Size Distributions (PSD). As small fragments are eroded from the surface of larger agglomerates, the size distribution of coarse material (agglomerates) shifts to the left (Figure 2). When a large agglomerate shatters into the smallest attainable fragments (often aggregates and where possible primary particles), the volume fraction of the coarse material decreases in time and that of fines increases as shown in Figures 1 and 2. In the case of rupture, which occurs through the gradual fragmentation of large agglomerates into smaller ones, the PSD moves to the left, also becoming narrower (Figures 1 and 2).

The process is typically carried out with power intensive devices. At high Reynolds numbers, turbulent stresses acting on agglomerates result in breakage. Agglomerates of a size, $L_{i}$, greater than the Kolmogoroff length scale, $\lambda_{k}$, smaller than macroscale of turbulence, $l$, i.e. $l \gg L_{i} \gg \lambda_{k}$, are broken up by inertial stresses:

$$
\tau \propto \rho \varepsilon^{2 \backslash 3} L_{i}^{2 \backslash 3}
$$

$\varepsilon$ being the local energy dissipation rate per unit mass of liquid. Agglomerates which are smaller than the Kolmogoroff length scale, $L_{i}<\lambda_{k}$, broken up by viscous subrange eddies as proposed by Baldyga et al (2008a):

$$
\tau \propto \mu\left(\frac{\varepsilon}{v}\right)^{1 / 2}=\rho \nu^{1 / 2} \varepsilon^{1 / 2}
$$


$v$ being the kinematic viscosity of the liquid. Different process devices used for the purpose include the stirred bead mill (Stenger et al, 2005; Kowalski et al., 2008; Schilde et al., 2010), ultrasonic dispersers (Baldyga et al., 2008b, 2009; Quarch et al., 2010) in-line rotor-stators (Baldyga et al., 2008a; Padron et al., 2008; Özcan-Taşkın et al., 2016), a batch rotor-stator (Xie et al., 2008) or high pressure devices (Sauter and Schuchmann, 2007; Seekkuarachchi et al., 2008 and Xie et al., 2008). Local energy dissipation rate in these devices, responsible for the breakup of agglomerates, can be orders of magnitude higher than the average energy dissipation rate. Some of the process devices, such as the ultrasonic disperser, are more commonly used during the formulation stage, whilst others, for example the in-line rotor-stator, are more suited for large scale operation. It is therefore not uncommon to use different devices at different scales of operation which makes process scale up a challenging task. A knowledge of the comparative performance of different process devices provides valuable input for the design and scale up of such processes.

This study was undertaken to assess the comparative performance of two batch rotor-stators as there is no published information on these designs for the breakup of nanoparticle clusters. The effects of varying power input on the smallest attainable size, mechanisms and kinetics of breakup were investigated. The test material used Aerosil 200V, is available in large quantities on the market and widely used in numerous products to improve mechanical properties, for example to reinforce rubber, as rheology modifiers, or to enhance surface effects of coatings (Ferch, 2005). As it is desirable for industrial applications to prepare a master batch to subsequently use in different formulations, the study also included the effect of particle concentration. 


\section{EXPERIMENTAL}

\subsection{Experimental Set-up}

The study was performed using a standard geometry, cylindrical, fully baffled glass tank of a diameter of $\mathrm{T}=0.103 \mathrm{~m}$ (Figure 3$)$.

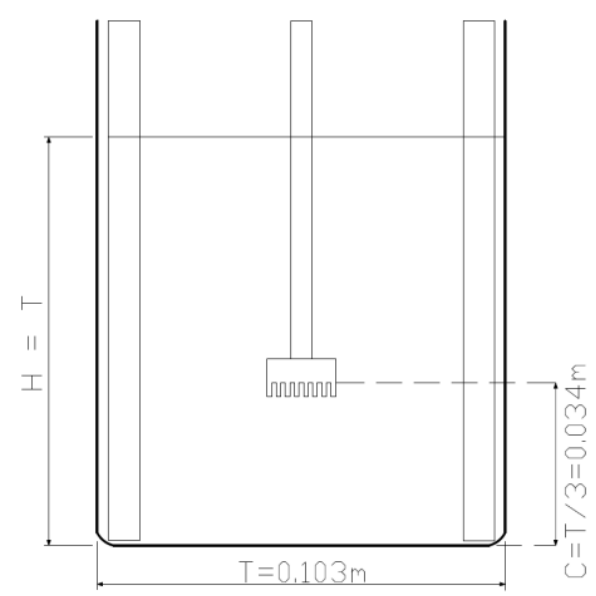

Figure 3 Schematic diagram of the mixing tank

Two different designs of batch rotor-stator heads used are shown in Figure 4 and their dimensions are provided in Table 1. The MICCRA D-9 head consists of a stator with 16 and a rotor with 8 teeth. The rotor of VMI, on the other hand, includes a 4 flat-bladed impeller as shown in Figure 4.b which is screwed onto a 16 teethed inner screen that rotates with the impeller. It may therefore be anticipated that the VMI will provide a better bulk homogeneity. The simple MICCRA D-9 design is characterised with narrow gaps of $1.20 \times 10^{-3} \mathrm{~m}$ between the stator teeth and $1.75 \times 10^{-3} \mathrm{~m}$ between the rotor teeth. The VMI stator, on the other hand, has 29 elliptic slots at an angle with a width of $2.00 \times 10^{-3} \mathrm{~m}$. Whilst this width is only slightly bigger than the inter-teeth gap of the MICCRA stator, the surface area of the slot is much bigger compared to the area of the inter-teeth gap of MICCRA which is smaller in length. The gaps between the teeth of the MICCRA rotor are also smaller than the inter-teeth gap of the VMI. 
These suggest that the local energy dissipation at a given average power input is likely to be higher with the MICCRA compared to the VMI.
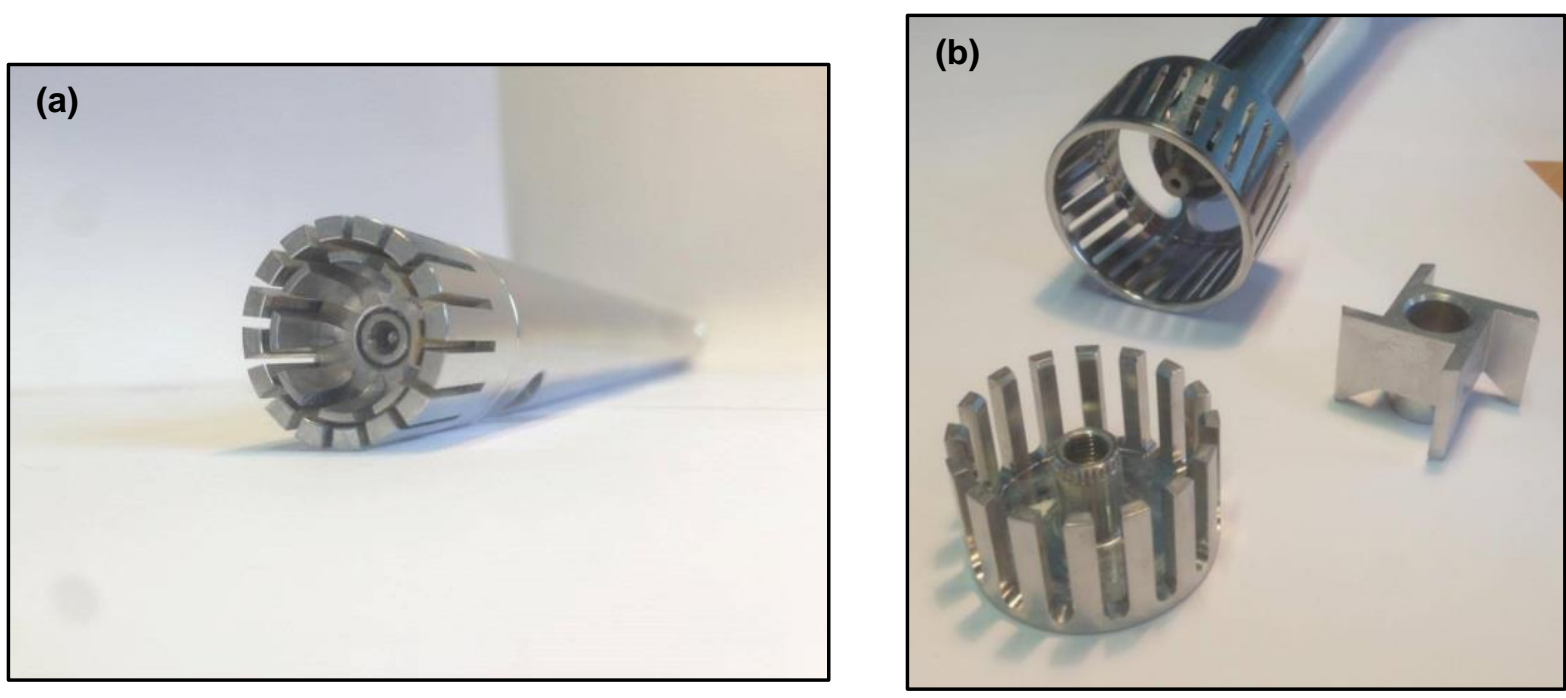

Figure 4- Rotor-Stator heads used - (a) MICCRA D-9 and (b) VMI

Table 1 Dimensions of the rotor-stators

\begin{tabular}{|c|c|c|c|c|c|c|c|}
\hline Part & $\begin{array}{c}\text { D } \\
(\mathbf{m})\end{array}$ & $\begin{array}{c}\text { Teeth gap } \\
\text { (m) }\end{array}$ & $\begin{array}{c}\text { Gap }(\mathbf{m}) \\
\text { between r-s }\end{array}$ & $\begin{array}{l}\text { Gap or slot } \\
\text { length }(m)\end{array}$ & $\begin{array}{c}\text { Thickness } \\
\text { (m) }\end{array}$ & $\begin{array}{l}\text { No. of } \\
\text { teeth }\end{array}$ & $\begin{array}{c}\text { No. of } \\
\text { slots }\end{array}$ \\
\hline \multicolumn{8}{|c|}{ MICCRA D-9 } \\
\hline Stator & 0.025 & 0.0012 & \multirow{2}{*}{$4.50 \times 10^{-4}$} & 0.0120 & 0.0019 & 16 & - \\
\hline Rotor & 0.014 & 0.0018 & & 0.0076 & 0.0010 & 8 & - \\
\hline \multicolumn{8}{|c|}{ VMI } \\
\hline Stator & 0.050 & 0.0020 & \multirow{2}{*}{$2.50 \times 10^{-4}$} & 0.0234 & 0.0028 & - & 29 \\
\hline Rotor & 0.045 & 0.0040 & & 0.0219 & - & 16 & - \\
\hline Impeller & 0.037 & - & - & - & 0.0029 & - & - \\
\hline
\end{tabular}

These devices were chosen as representative rotor-stator designs with only teeth (MICCRA) or blades, teeth and holes (VMI), so that overall conclusions obtained can be used as a guideline on the performance of other batch rotor-stators of similar designs. 


\section{Materials}

Experiments were conducted using hydrophilic fumed silica particles, Aerosil 200V, manufactured by Evonik Industries. Deionised water was used as the continuous phase.

The primary particle size is given as $12 \mathrm{~nm}$ by the manufacturers. The synthesis of fumed silica can be described essentially as a continuous flame hydrolysis of silicon tetrachloride $\left(\mathrm{SiCl}_{4}\right)$. Collision, sticking and partial fusion of primary particles during manufacture result in the formation of aggregates that are held together by sintering bridges. While leaving the flame and cooling, these aggregates continue to collide forming agglomerates of aggregates (Barthel, 1995; Ulrich and Riehl, 1982). Therefore, due to the manufacturing method employed, the powder on the market consists of clusters of a broad range of sizes.

This is native, unmodified fumed silica with a surface covered with silanol ( $\mathrm{Si}-\mathrm{OH})$ groups to the tune of $\sim 2.5[\mathrm{SiOH}]$ groups $/ \mathrm{nm}^{2}$, has a BET surface area of $\sim 200 \mathrm{~m}^{2} / \mathrm{g}$ and tap density of 50 to $120 \mathrm{~g} / \mathrm{l}$ as detailed in the manufacturer's product brochures.

Dispersions were prepared at three concentrations of 1,5 and $10 \% \mathrm{w}: \mathrm{w}$.

\section{Experimental Procedure and Conditions}

A well-defined procedure was followed for the preparation of all the pre-dispersions to minimise any variations at the start of the experiment. After the addition of the appropriate amount of powder, the pre-dispersion was mixed using a pitched blade turbine in a fully baffled tank at a stirrer speed of $140 \mathrm{rpm}$ for 30 minutes. The dispersions produced had a $\mathrm{pH}$ of around 4.5 . 
Break-up experiments were run for 3 hours over a range of speeds. The fixed speeds the MICCRA was operated were 11,000,16,000 and 21,000 rpm, which corresponded to a specific power input range of $15.15-114.60 \mathrm{~kW} \mathrm{~m}^{-3}$ over a Reynolds number range of 6,482 to 53,130 depending on the particle concentration. With the VMI, the speed range was lower: 2,000, $2,500,3,000$ rpm corresponding to a Reynolds number range of 10,607 to 68,310 and a specific power input range of around 20.75 to $76.12 \mathrm{~kW} \mathrm{~m}^{-3}$.

The evolution of Particle Size Distributions (PSD) obtained from samples taken during processing was used to monitor the process. Rheology of the pre-dispersion and final dispersion was also determined.

\section{Experimental Techniques}

The samples were analysed using the Malvern Mastersizer® S. A 'polydisperse' analysis model was selected in the calculation of the PSD and a complex refractive index of $1.46+0.1 \mathrm{i}$ was used.

Results from repeatability tests show excellent agreement from two independently run experiments as shown in Figure 5. 


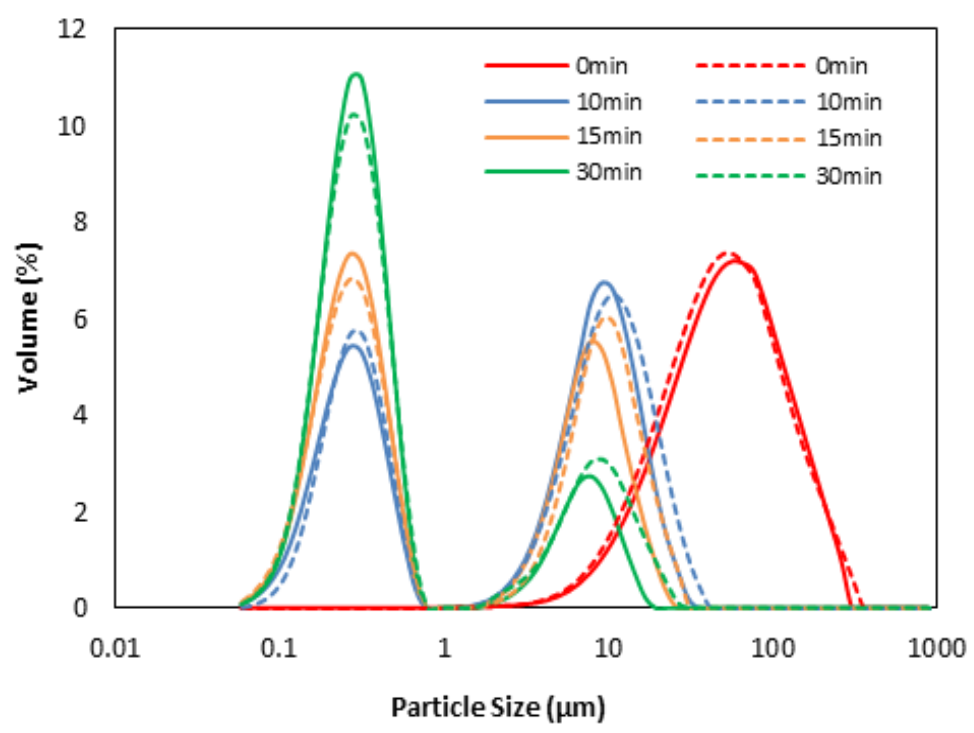

Figure 5. Reproducibility of PSD from two independently run experiments at $10 \%$ wt. Aerosil 200V using the MICCRA D-9 rotor-stator at 21,000 rpm $\left(114.6 \mathrm{~kW} \mathrm{~m}^{-3}\right)$

The rheology measurements were taken using a HAAKE VT-550 with the bob-and-cup double gap geometry. All samples were of Newtonian behaviour and the rheology of the fresh predispersion and final dispersion was practically the same. The viscosity of the $1 \%$ dispersion was too low to be measured reliably and hence was taken to be water-like. For 5 and $10 \%$, the viscosity was measured $3.7 \times 10^{-3}$ and $6.7 \times 10^{-3} \mathrm{~Pa}$ s respectively. At such low viscosities, corresponding to Reynolds numbers in the range of $7 \times 10^{3}-7 \times 10^{4}$ the bulk circulation within the feed tank was observed to be sufficient with no evidence of compartmentalisation.

The morphology of selected samples was examined using the JEOL 7800F and the Leo Zeiss 1530-VP Field Emission Gun Scanning Electron Microscope (FEGSEM).

Power input was determined using the calorimetry technique. The power numbers for the MICCRA D-9 and VMI were found to be 2.56 and 2.40 respectively. This is within the range of power numbers for batch rotor-stators in the turbulent regime: 1-3 (Padron, 2001; Utomo et 
al, 2008). Doucet et al (2005), who used a slightly different VMI geometry which had a stator with 8 circular orifices on the upper part, in addition to the slots on the side and a rotor which only included the 4-bladed impeller, reported a comparable power number of 3.0 in the turbulent regime. Their results show that the Po is constant at Reynolds numbers greater than 100.

\section{RESULTS AND DISCUSSIONS}

Particle sizes for the pre-dispersions were of the order of 10's of microns. During the course of processing, the PSD had a distinctive bi-modal feature with both of the batch rotor-stators (Figures 5 and 6). This is in line with previously reported findings with this material using inline rotor-stators or valve homogenisers (Baldyga et al, 2008a; Özcan-Taskin et al, 2009 and Xie et al, 2008).

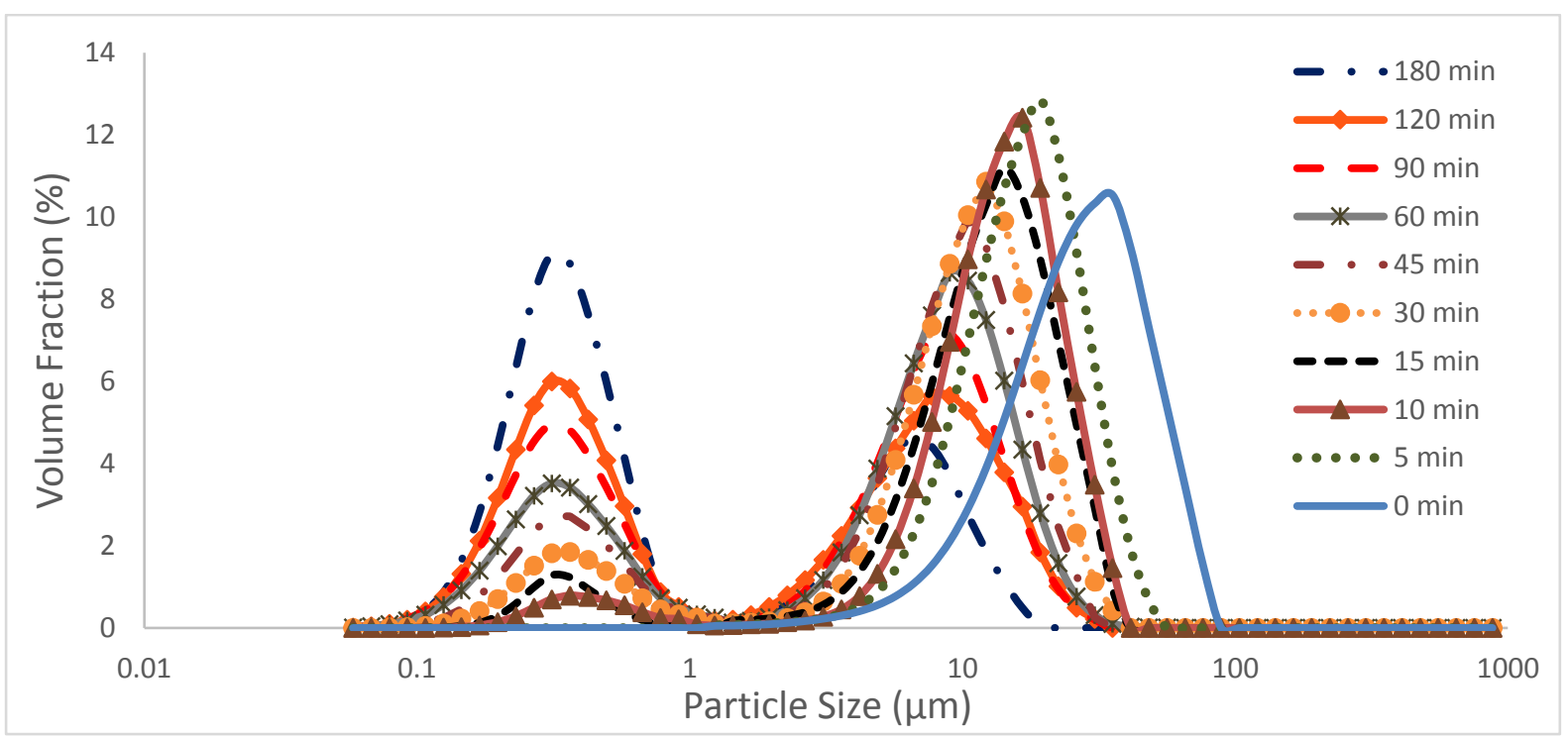

Figure 6. The evolution of PSD in time during the break up of $1 \%$ Aerosil 200V using the VMI operated at $3000 \mathrm{rpm}\left(70.03 \mathrm{~kW} \mathrm{~m}^{-3}\right)$ 
Due to this bi-modal size distribution, using an overall mean diameter can hide important features of the dispersion. Data were therefore analysed for coarse $(>1 \mu \mathrm{m})$ and submicron material separately. Figure 7 shows the evolution of the Sauter mean diameters $\left(d_{32}\right)$ for the whole dispersion along with those for fines $(<1 \mu \mathrm{m})$ and coarse material. In addition to the evolution of the Sauter mean diameters of fines and coarse material, rates of fines generation and size reduction of coarse material are presented and discussed in the following Sections.

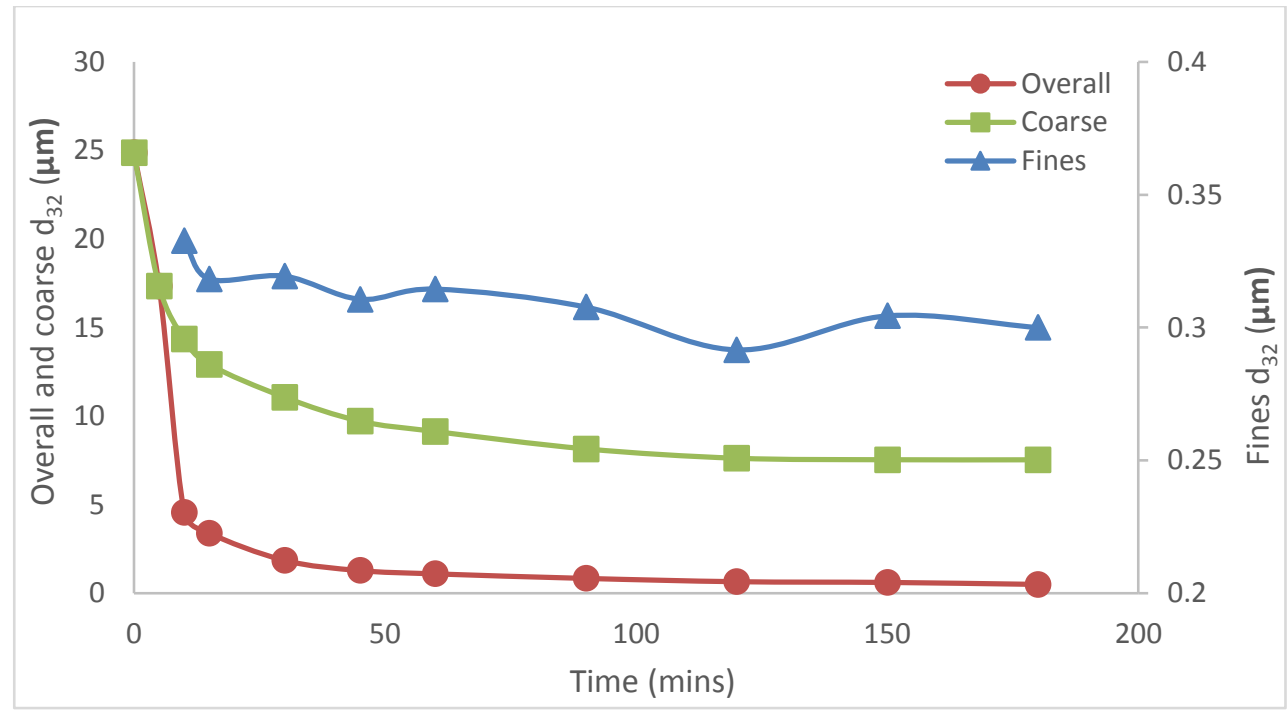

Figure 7. Evolution of Sauter mean diameters for the whole dispersion, coarse material and fines $(<1 \mu \mathrm{m})$ during the dispersion of 5\% wt. Aerosil200V using MICCRA at 11,000 rpm $\left(15.87 \mathrm{~kW} \mathrm{~m}^{-3}\right)$

\section{Mechanism of breakup and dispersion fineness}

The evolution of Particle Size Distributions (PSD) shown Figures 5 and 6 indicate that small fragments are chipped off larger agglomerates during processing and consequently the volume 
fraction of coarse agglomerates reduces and the distribution shifts towards $1 \mu \mathrm{m}$. The fragments eroded from the surface of larger agglomerates are of a given size range and increase in volume over time. This evolution of the size distribution is indicative of erosion being the dominant break up mechanism. This was observed under all conditions for both the MICCRA and VMI. It is also in agreement with findings using in-line rotor-stators with this particle-liquid pair (Özcan-Taşkın, 2009, 2016).

The size of finest material is of the order of some 100's of nanometers, i.e. an order of magnitude greater than the primary particle size. This would be expected due to the manufacturing method employed. Hence, the dispersion fineness is determined by the size of aggregates.

An analysis of all the results obtained with the MICCRA at three particle concentrations and over a range of specific power input values in the range of about 15 to $115 \mathrm{~kW} \mathrm{~m}^{-3}$, show that the Sauter mean diameter of fines is independent of the operating conditions or particle concentration (Figure 8). This also holds for the VMI: data presented in Figure 9 further illustrate that the rotor-stator geometry also does not affect the dispersion fineness and the Sauter mean diameter of aggregates is in the range of 300 to $450 \mathrm{~nm}$. 


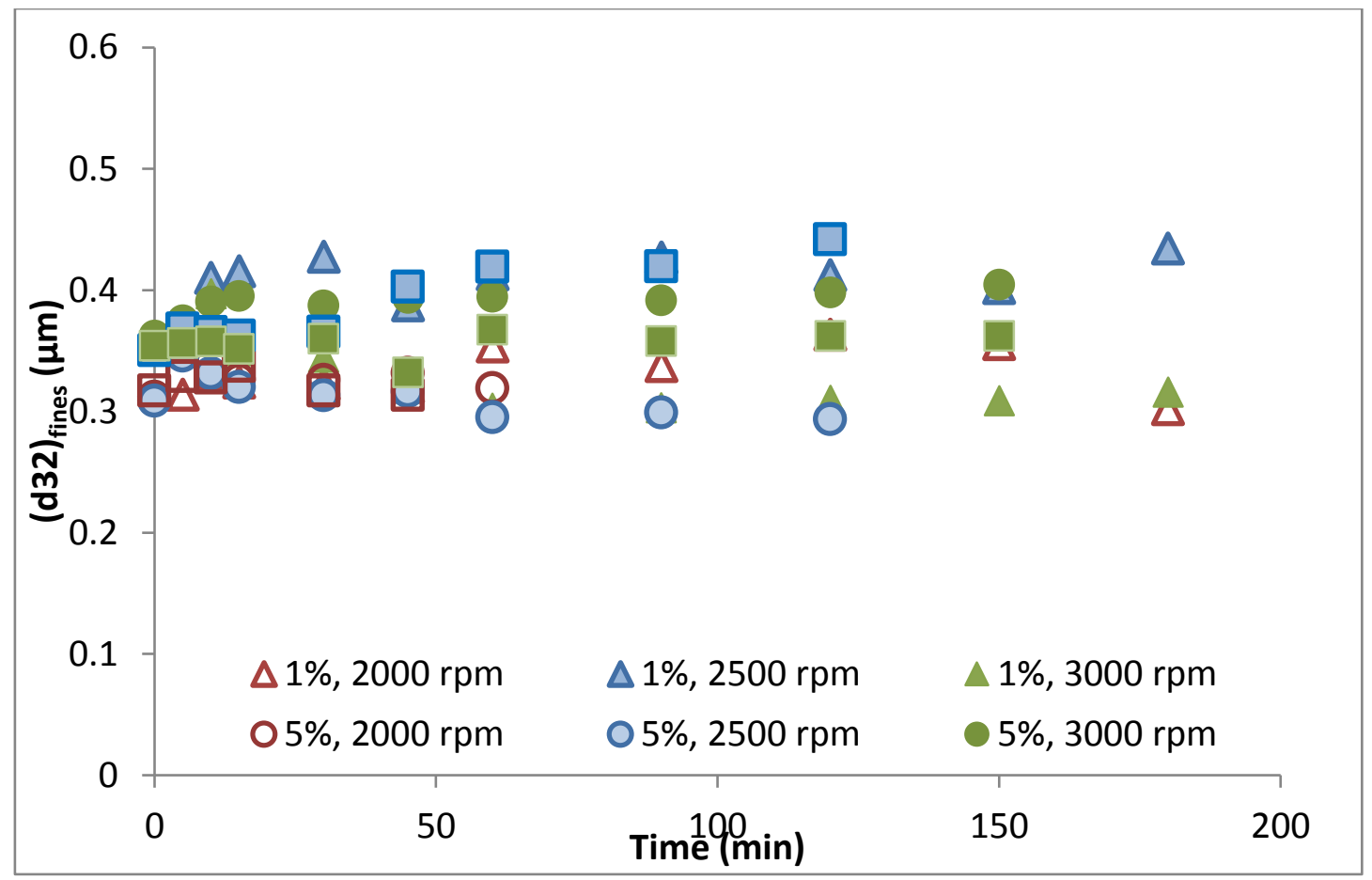

Figure 8. Sauter mean diameters of fines obtained using the VMI at three concentrations over a range of operating conditions (specific power input range of $20.75-76.12 \mathrm{~kW} \mathrm{~m}^{-3}$ )

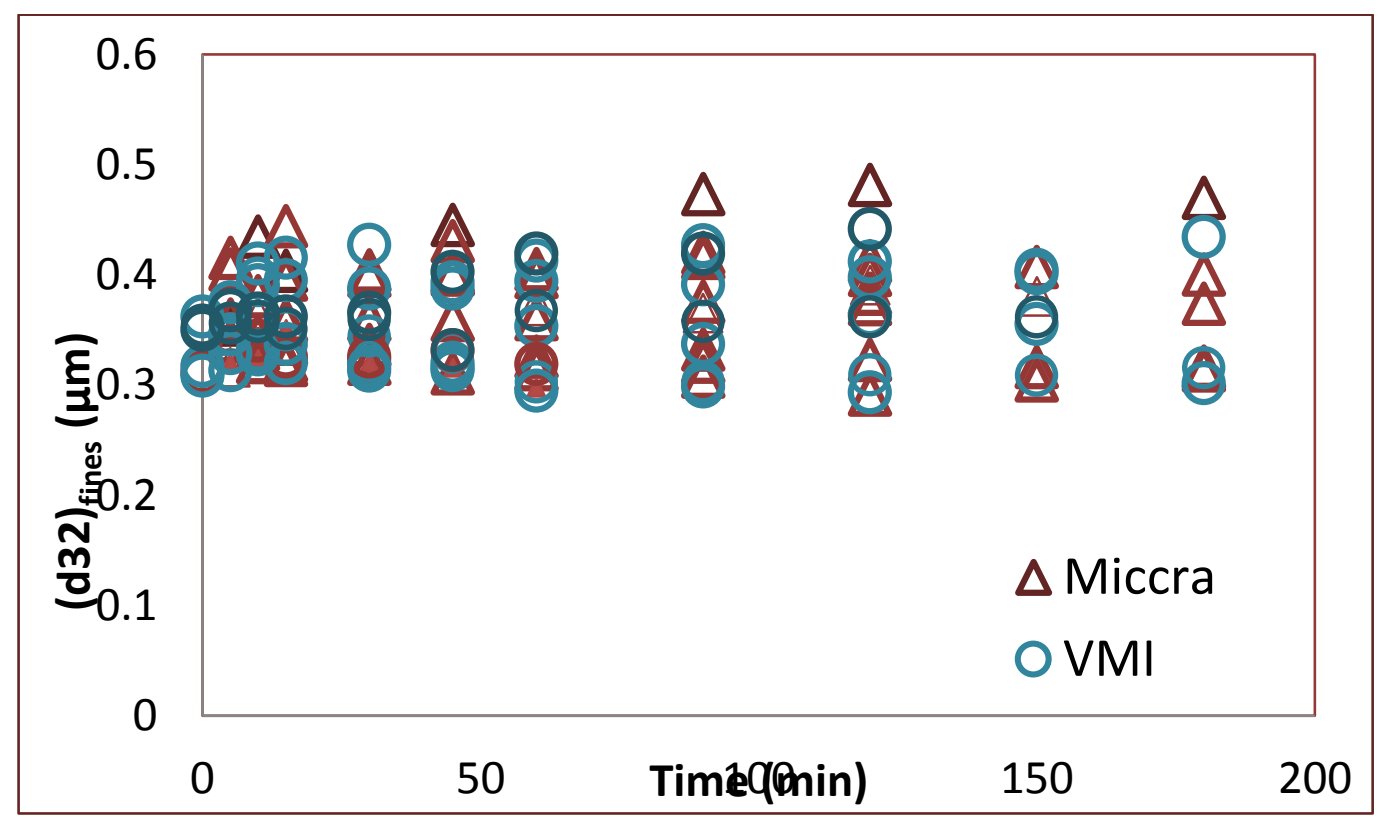

Figure 9. Sauter mean diameters for fines generated during processing with the two rotorstators, MICCRA and VMI. 
A representative image obtained for one the dispersions prepared in this study is shown in Figure 10.

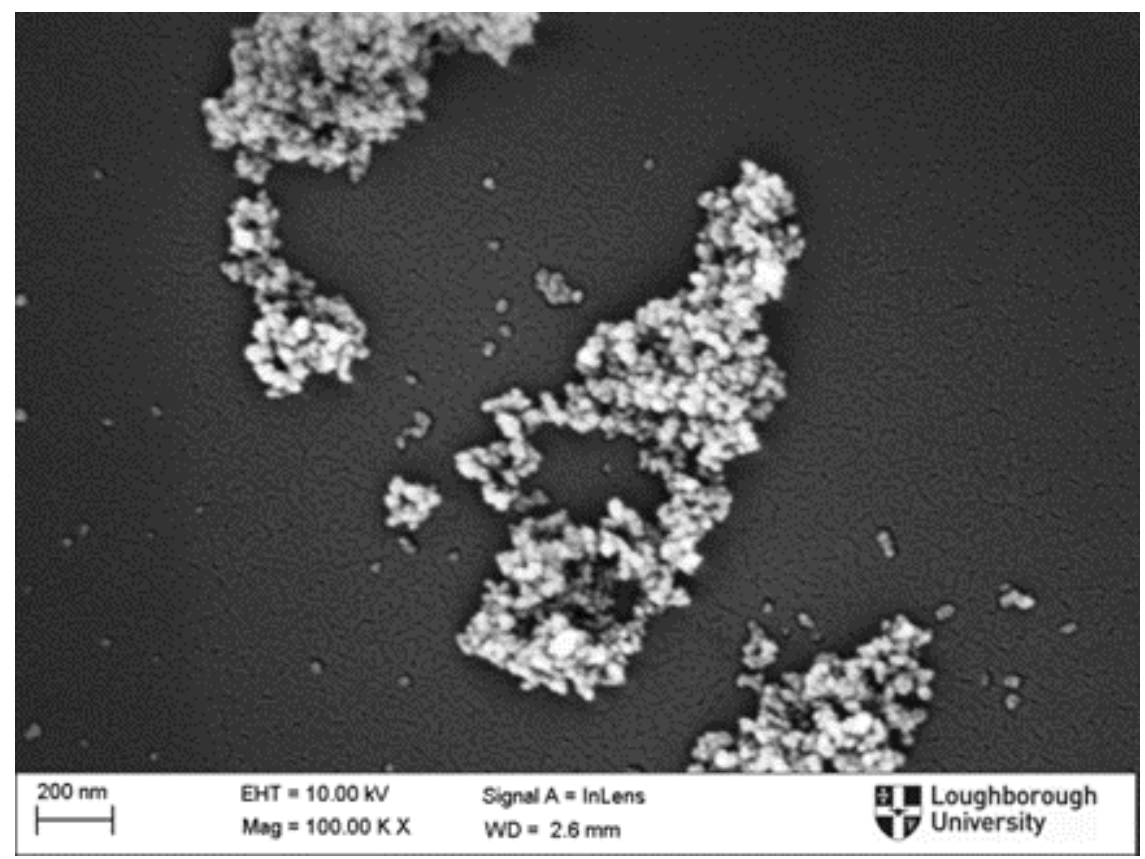

Figure 10. SEM images from Aerosil 200V-in-water dispersion

The results may well be different with a different continuous phase due to differences in chemical interactions and particle-liquid affinity.

\section{Effect of operating conditions on the kinetics of breakup}

Whilst the mechanism of break up and dispersion fineness are independent of the operating conditions or the rotor-stator design, the kinetics of break up increases with the rotor speed, i.e. the power input. The evolution of the particle size distributions for $10 \%$ wt. Aerosil obtained using the MICCRA at two speeds shows that starting with pre-dispersions of comparable PSDs, the break up progresses much more rapidly at a rotor speed of $16,000 \mathrm{rpm}$ compared to 11,000 
rpm, which is evident even at the end of 5 minutes of processing (Figure 11). This increase in rotor speed corresponds to a three-fold increase in the specific power input.

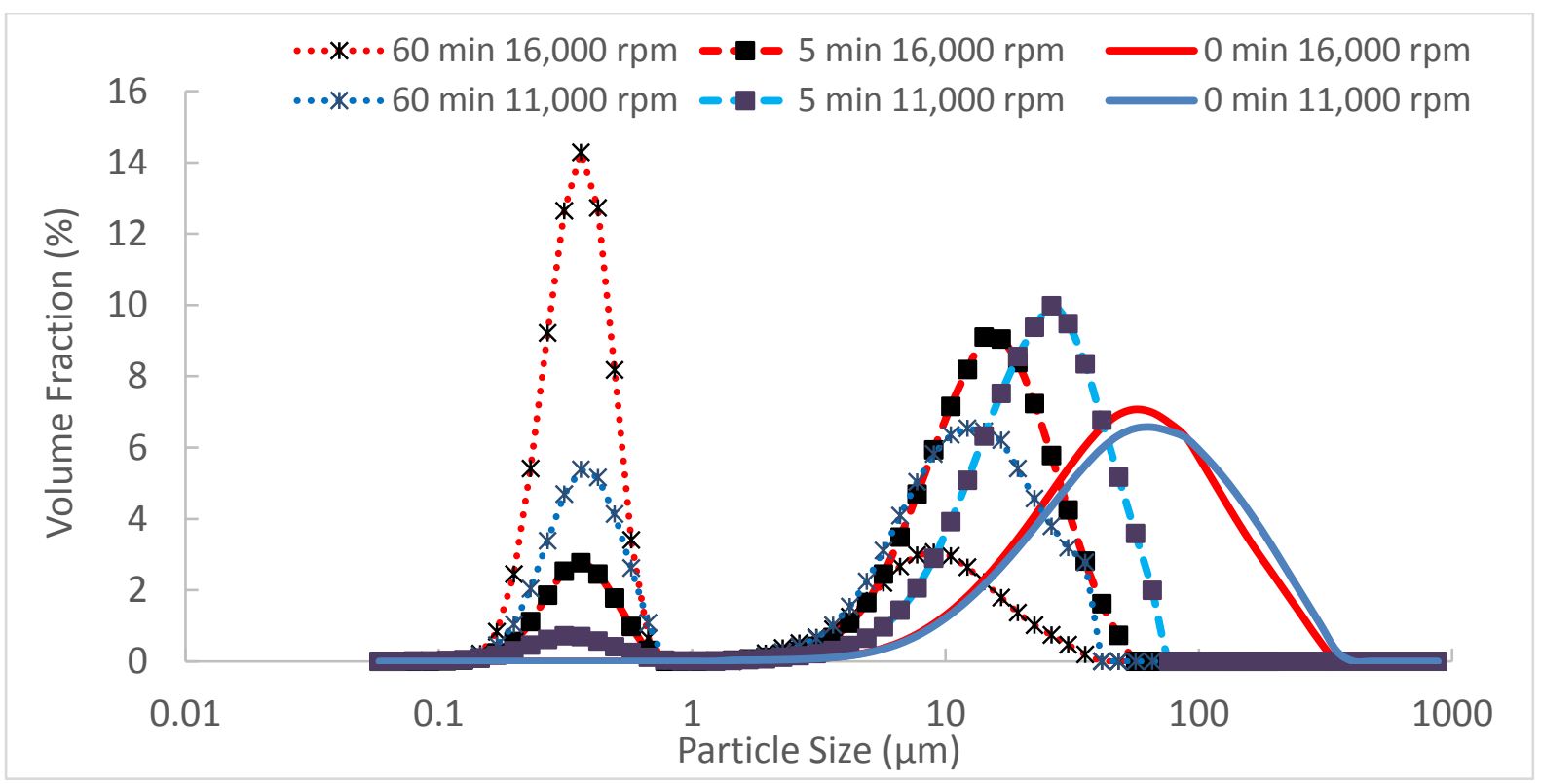

Figure 11. Effect of power input on PSD during the processing of $10 \%$ Aerosil 200V-in-water using the MICCRA at $11,000 \mathrm{rpm}\left(16.47 \mathrm{~kW} \mathrm{~m}^{-3}\right)$ and $16,000 \mathrm{rpm}\left(50.69 \mathrm{~kW} \mathrm{~m}^{-3}\right)$

Increasing the rotor speed, thereby the average power input, increases the local energy dissipation rate as was reported by Özcan-Taşkın et al (2011) for in-line rotor-stators and this results in faster breakage of the agglomerates. Break up kinetics evaluated in terms of fines generation rate allows results to be analysed and presented over a wider range of conditions than that covered in Figure 11 with PSDs. For a given particle concentration of $1 \%$ wt., the increase in the rate of reduction of coarse material volume fraction with increasing power input is shown in Figure 12.a for both the MICCRA and VMI. Similarly, break up kinetics can be studied through the fines generation rate which increases with an increase of power input as shown in Figure 12.b. 


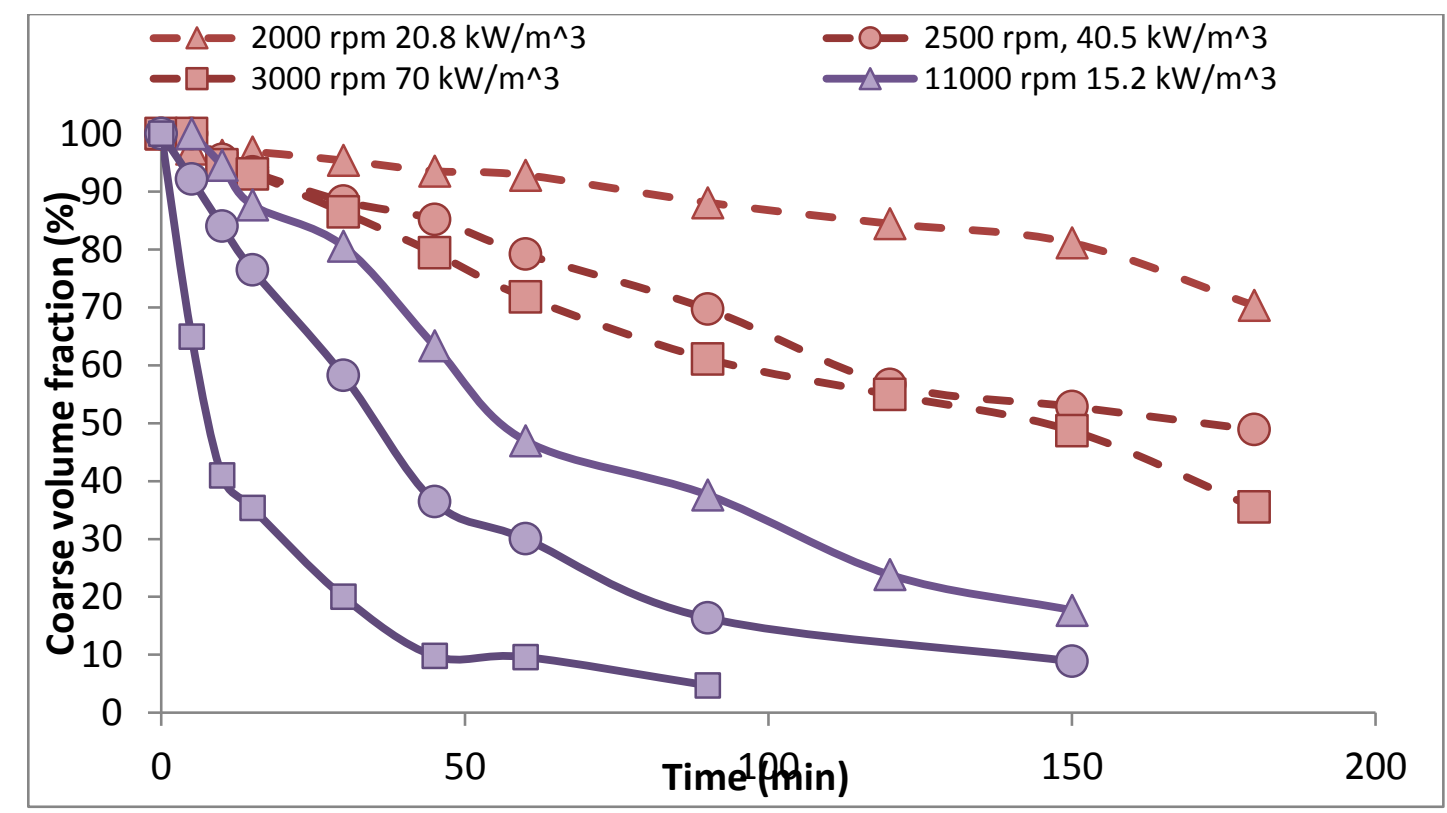

Figure 12. Effect of rotor speedlpower input on break up kinetics for $1 \%$ wt Aerosil 200V with both the VMI (dashed lines) and MICCRA (solid lines) analysed in terms of (a) rate of reduction of coarse material volume (b) fines generation rate.

Evolution of the Sauter mean diameter for coarse material also provides useful information in terms of break up kinetics. As can be seen in Figure 13, for a wide range of operating conditions, the size reduction becomes steeper as the rotor speed and hence the power input is increased. It is also worth noting that the decrease in time of the coarse material $d_{32}$ as the aggregates are chipped off the surface of large agglomerates is indicative of erosion being the dominant breakup mechanism. 


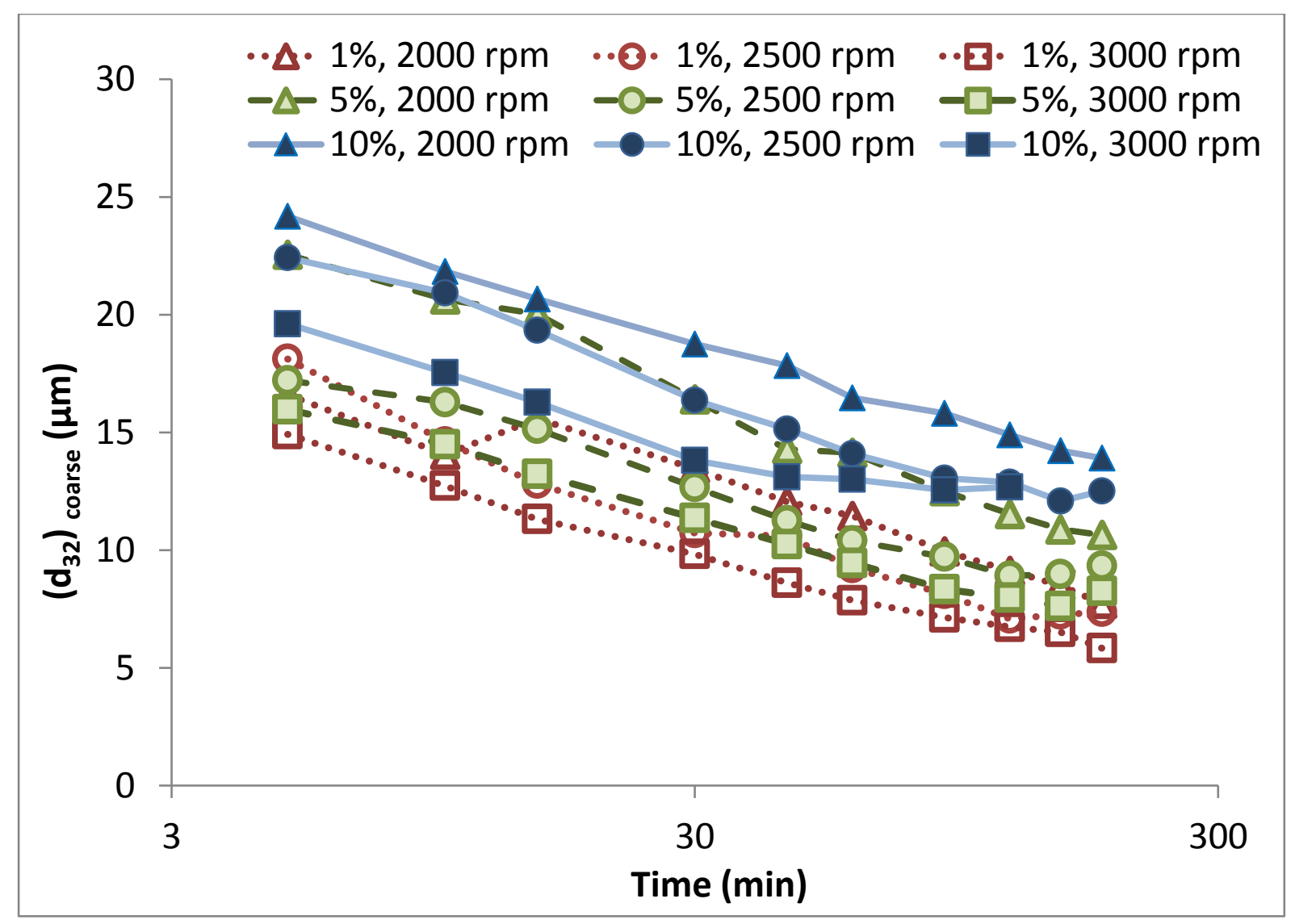

Figure 13. Evolution of the Sauter mean diameters of coarse material using the VMI over a range of operating speeds (corresponding to a specific power input range of 21 to $76 \mathrm{~kW} \mathrm{~m}^{-3}$ ) and particle concentrations

\section{Effect of particle concentration}

Different formulations can require different particle concentrations; it may also be desirable to prepare a master batch which is easier to store and transport prior to incorporating into the final formulation. Therefore, the effect of particle concentration on break up was included in the study.

The Sauter mean diameter for the smallest attainable size or mechanism of break up do not depend on the particle concentration as can be seen in Figures 6 to 9. Break up kinetics studied through the evolution of the Sauter mean diameter for coarse material shows that for a given 
specific power input as the concentration is increased, break up kinetics slows down during processing (Figure 13). Data presented on the basis of energy density are shown in Figure 14 for different particle concentrations. The decrease in break up kinetics due to a ten-fold increase in particle concentration appears to be more prominent than that due to the variation of the specific power input at a given concentration which ranged from $21-23$ to $70-76 \mathrm{~kW} \mathrm{~m}^{-3}$.

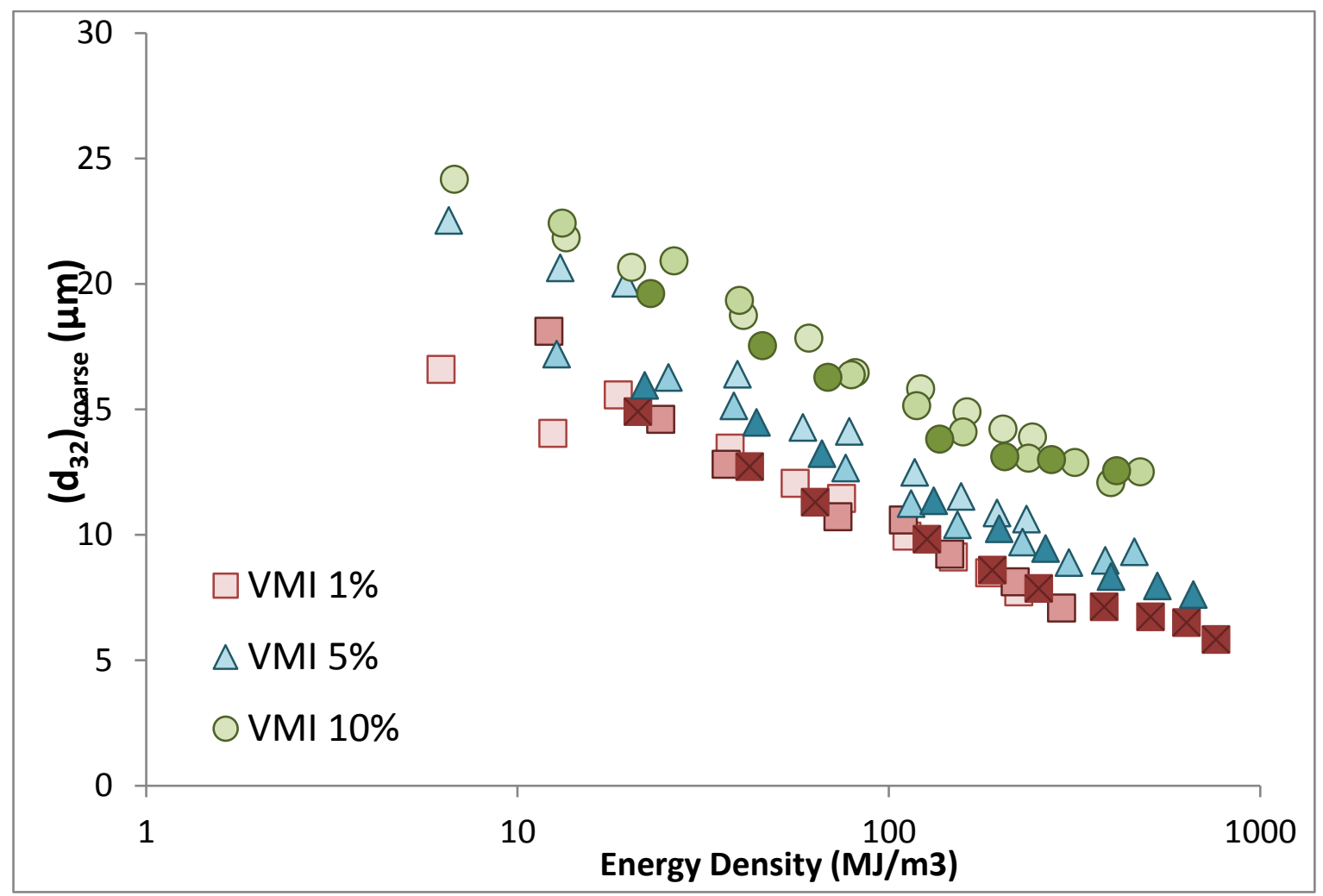

Figure 14. Effect of particle concentration on the evolution of the Sauter mean diameter for coarse material using the VMI. Data for a given concentration are presented in different shades for different power input values

At an energy density of $100 \mathrm{MJ} \mathrm{m}^{-3}$, coarse volume fraction in a $1 \%$ wt Aerosil dispersion can be reduced to about $20 \%$ using the MICCRA operated at $11,000 \mathrm{rpm}\left(15.2 \mathrm{~kW} \mathrm{~m}^{-3}\right)$ as shown in Figure 15. When the concentration is increased to $10 \% \mathrm{wt}$, the coarse volume fraction found 
in the dispersion is higher at this energy density level: about 50\%. It is also worth pointing out that the effect of particle concentration seems to be less pronounced with the VMI.

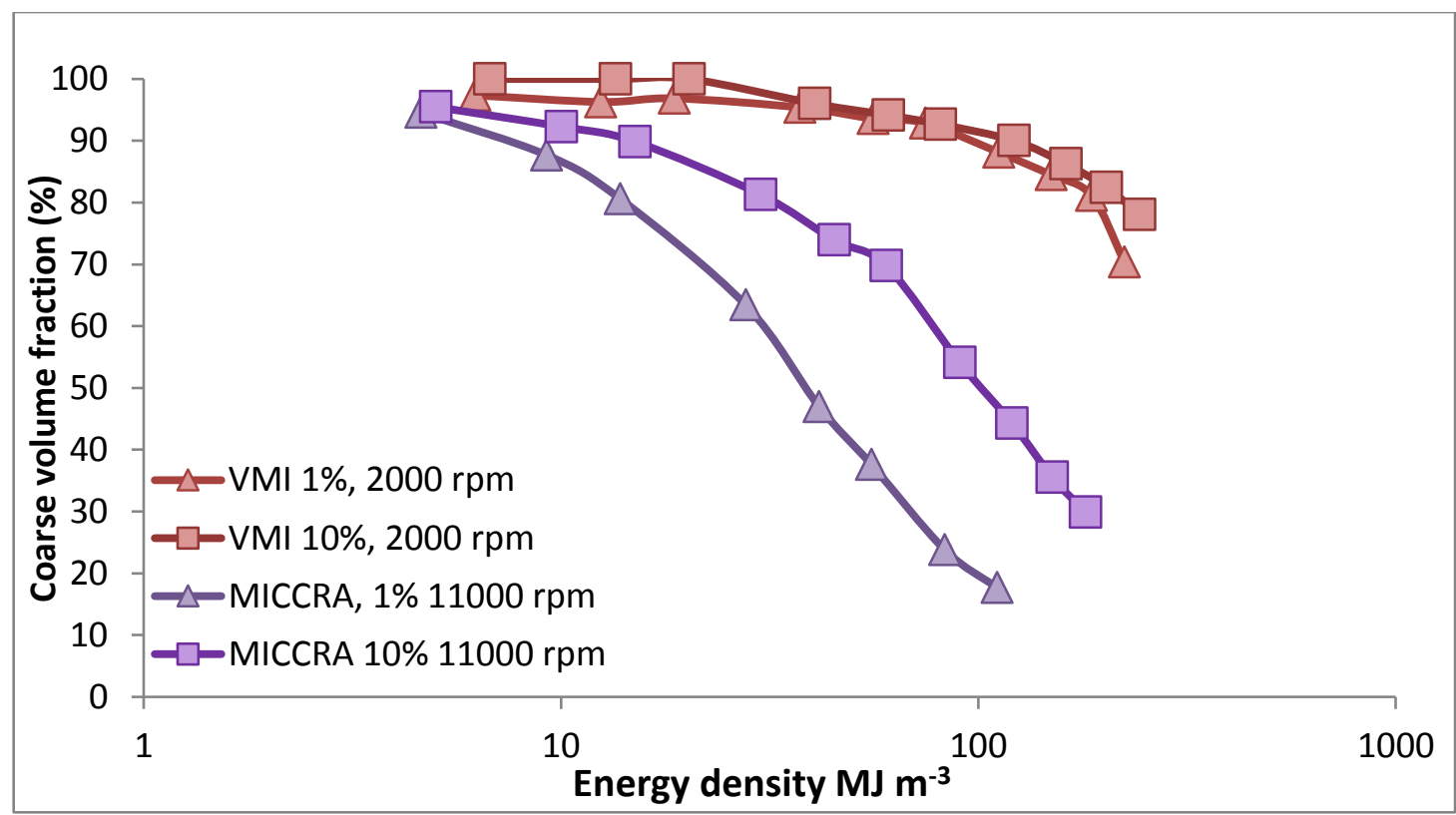

Figure 15. Effect of increasing the particle concentration on the rate of coarse volume fraction reduction for both the VMI (operated at 2,000 rpm, 20.8 and $22.6 \mathrm{~kW} \mathrm{~m}^{-3}$ for 1 and $10 \% \mathrm{wt}$ ) and MICCRA (operated at 11,000 rpm, 15.2 and $16.5 \mathrm{~kW} \mathrm{~m}^{-3}$ for 1 and $10 \% \mathrm{wt}$ )

When the same data sets are analysed on the basis of energy input per mass of particles (rather than dispersion volume), it can be seen in Figure 16 that processing at a higher particle concentration can be beneficial. Whilst the process to achieve a certain fines volume fraction becomes longer as the particle concentration is increased, it is still more energy efficient to prepare a masterbatch at a higher particle concentration which would also present advantages in terms of storage and transport. 


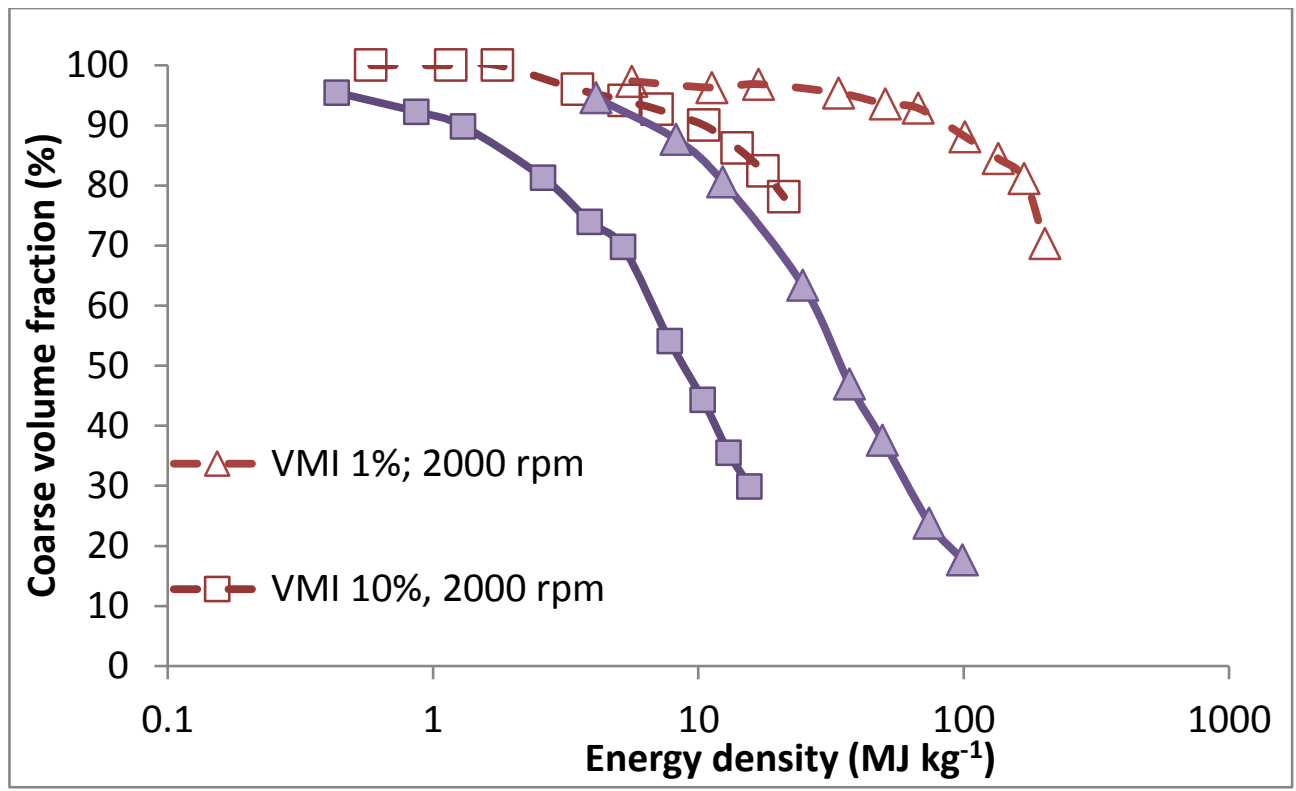

(a)

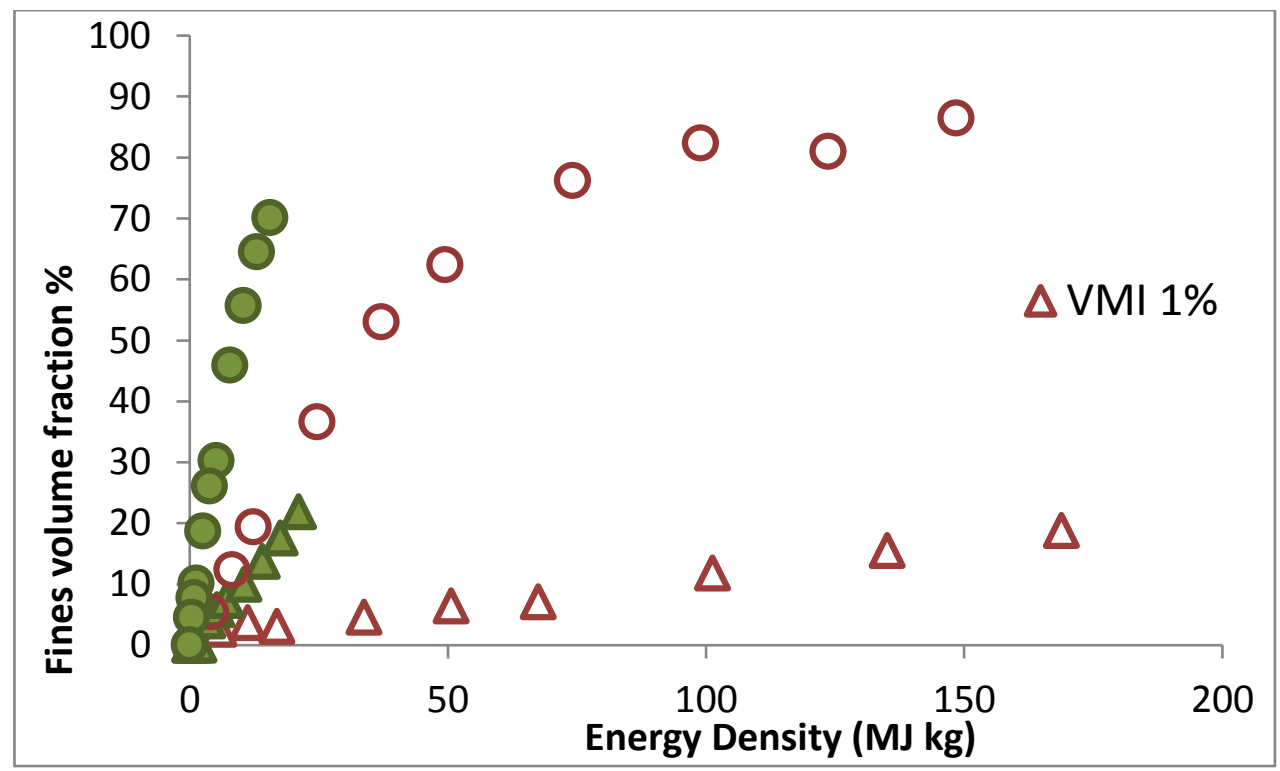

(b)

Figure 16. Effect of particle concentration on break up kinetics assessed on the basis of energy per mass of particles (a) coarse material volume reduction; (b) fines volume fraction with the VMI (operated at 2,000 rpm, 20.8 and $22.6 \mathrm{~kW} \mathrm{~m}^{-3}$ for 1 and $10 \% \mathrm{wt}$ ) and MICCRA (operated at $11,000 \mathrm{rpm}, 15.2$ and $16.5 \mathrm{~kW} \mathrm{~m}^{-3}$ for 1 and $10 \% \mathrm{wt}$ ) 


\section{Importance of rotor-stator geometry on break up kinetics}

As discussed above, breakup occurs through erosion irrespective of the rotor-stator design. The smallest attainable size (aggregate size) also does not depend on the rotor-stator design. Differences were noted in term of breakup kinetics with these designs. Of the two rotor-stators used, MICCRA has faster break up kinetics than the VMI at comparable specific power input values. This can be seen in Figure 12 in terms of both the size reduction of coarse material and fines generation rate. In order to reach a fines volume fraction of around $30 \%$, the VMI requires 180 min of processing at $20.8 \mathrm{~kW} \mathrm{~m}^{-3}$. This can be achieved in 25 min using the MICCRA at a comparable, in fact slightly lower, specific power input of $15.2 \mathrm{~kW} \mathrm{~m}^{-3}$. At higher specific power input values of 40.5 and $46.6 \mathrm{~kW} \mathrm{~m}^{-3}$, the processing time required is about 90 and 17 min for the VMI and MICCRA respectively. Data analysed on the basis of energy density also demonstrate that the MICCRA is faster in breaking up nanoparticle clusters compared to the VMI at both 1 and 10\% particle concentration (Figure 15).

There are distinctive differences in the designs of the two rotor-stators. The surface area of the openings on the rotor and stator of the VMI are larger than the gap between the teeth of the MICCRA. It would therefore be anticipated that the local energy dissipation rate with the MICCRA would be higher than with the VMI. Whilst the MICCRA is of a simple design with two sets of teeth, the VMI design includes a rotating impeller in a slotted cage. Hence, it may be postulated that a greater proportion of the average power input contributes towards convective flows in the bulk. This design would therefore be expected to provide a better bulk movement and homogeneity and hence may well outperform the MICCRA in larger installations andlor more viscous dispersions. For such cases, an additional impeller is likely to be required if the MICCRA or a similar design is used. 
This overall trend of rotor-stator designs with smaller holes or narrower gaps having a higher break up kinetics was also reported by Özcan-Taşkın et al (2016) for different in-line rotorstator designs.

\section{CONCLUSIONS}

Two rotor-stator designs were used to study the breakup of clusters of nanoscale silica particle clusters to determine the mechanisms and kinetics of break up and assess how fine a dispersion can be obtained. The effects of power input and particle concentration were studied.

The Sauter mean diameter of the smallest size that could be obtained was about $350-400 \mathrm{~nm}$ regardless of the operating conditions or design of the rotor-stator head.

Based on the results obtained, it could be concluded that the break up mechanism for Aerosil $200 \mathrm{~V}$ in a batch rotor-stator system is predominantly erosion across the range of conditions covered regardless of the particle concentration, power input (15 to $\left.115 \mathrm{~kW} \mathrm{~m}^{-3}\right)$ or rotor-stator design. The bimodal particle size distribution obtained requires the analysis of the evolution of data for fines and coarse material separately.

With both rotor-stators, the rate of the reduction of coarse particles and fines generation rate increased with increased energy density at a given particle concentration.

As the particle concentration was increased, break up kinetics slowed down when assessed on the basis of processing time or energy density. It could however be shown that processing high concentrations may still be beneficial as the breakup rate on the basis of energy input per mass of particles is higher. This also presents advantages in terms of storage and transport. 
A comparison made on the basis of average power input showed that the break up kinetics is faster for the MICCRA D-9 compared to the VMI. This may be attributed to higher levels of turbulence in the proximity of the MICCRA which has narrower openings on both the rotor and stator compared to the VMI design which also includes a 4-bladed impeller.

It would be worth investigating the performance of these designs in larger installations and more viscous dispersions where the VMI may well provide a better overall bulk homogeneity and product properties away from the rotor-stator head of the MICCRA may be different unless it is used with an impeller to provide bulk blending. Future work on a quantitative study the flow fields generated by these different rotor-stator designs using techniques such the PIV or LDA would provide valuable information for the evaluation of the effect of geometry. 


\section{ACKNOWLEDGEMENTS}

The authors gratefully acknowledge YtronQuadro making the VMI available for this study.

Dr Keith Yelling of Loughborough University Materials Engineering Department obtained electron microscopy images.

\section{NOMENCLATURE}

C impeller off-bottom clearance

$(\mathrm{m})$

$D \quad$ rotor diameter

$d_{32} \quad$ Sauter mean diameter

$H \quad$ Liquid height in tank

$l \quad$ macroscale of turbulence

$L_{i} \quad$ agglomerate size

$P \quad$ power input

$T \quad$ tank diameter

\section{Greek}

$\varepsilon \quad$ local energy dissipation rate per unit mass of liquid $\quad\left(\mathrm{m}^{2} \mathrm{~s}^{-3}\right)$

$\sigma \quad$ diameter of surface atom $\quad(\mathrm{m})$

$\lambda_{\mathrm{k}} \quad$ Kolomogov microscale $\quad$ (m)

$\mu \quad$ dynamic viscosity $\quad\left(\mathrm{kg} \mathrm{m}^{-1} \mathrm{~s}^{-1}\right)$

$v \quad$ kinematic viscosity $\quad\left(\mathrm{m}^{2} \mathrm{~s}^{-1}\right)$

$\rho$ density $\quad\left(\mathrm{kg} \mathrm{m}^{-3}\right)$

$\tau \quad$ stresses acting on particle clusters $\quad(\mathrm{Pa})$ 


\section{REFERENCES}

Bałdyga, J.; Orciuch, W.; Makowski, Ł.; Malik, K.; Özcan-Taşkın, G. N.; Eagles, W. (2008a) "Dispersion of nanoparticle clusters in a rotor-stator mixer" Ind. Eng. Chem. Res., 47 (10), 3652 -3663. DOI 10.1021/ie070899u.

Baldyga, J.; Makowski, Ł.; Orciuch, W.; Sauter, C. and Schuchmann, H. P. (2008b) "Deagglomeration processes in high-shear devices" Chem. Eng. Res. Des., Vol.86 (12), pp.1369-1381 (doi: 10.1016/j.cherd.2008.08.016).

Bałdyga, J.; Makowski, L.; Orciuch, W.; Sauter, C.; Schuchmann, H.P. (2009) “Agglomerate dispersion in cavitating flows” Chem. Eng. Res. Des. Vol. 87 (4), p: 474-484.

Barthel, (1995) "Surface interactions of group-modified fumed silica" Colloids and Surfaces A: Physicochemical and Engineering Aspects, Vol. 101, Issue 2-3, p: 217-226 http://dx.doi.org/10.1016/0927-7757(95)03179-H 1995

Doucet, L.; Ascanio, G.; Tanguy, P. (2005) "Hydrodynamics Characterization of rotor-stator mixer with viscous fluids" Trans. IChemE, 83 (A10), 1186- 1195. Doi:10.1205/cherd.04254

Ferch H. K. (2005) "Industrial synthetic silicas in powder form" in Colloidal Silica: Fundamentals and Applications Editors Bergna, H.E.; Roberts, W.O.

Kowalski, A. J., Watson, S., \& Wall, K. (2008) "Dispersion of nanoparticle clusters by ball milling" Journal of Dispersion Science and Technology, Vol 29 (4). 600-604, (doi:10.1080/01932690701729609).

Özcan-Taşkın; G. N., Padron, G., \& Voelkel, A. (2009) "Effect of particle type on the mechanisms of breakup of nanoscale particle clusters" Chem. Eng. Res. Des. Vol 87, No.4, p: 468-473, (DOI 10.1016/j.cherd.2008.12.012)

Özcan-Taşkın, G., Kubicki, D., \& Padron, G. A. (2011). Power and flow characteristics of 
three rotor-stator heads. The Canadian Journal of Chemical Engineering, 89(5), 1005-1017. doi:10.1002/cjce.20553

Özcan-Taşkın, N.G., Padron, G.A., \& Kubicki, D. (2016). Comparative Performance of InLine Rotor-Stators for Deagglomeration Processes. Chemical Engineering Science, 156, 186196 http://dx.doi.org/10.1016/j.ces.2016.09.023

Padron, G. A. (2001) “Measurement and comparison of power draw in rotor-stator mixer" MSc thesis, University of Maryland, College Park, MD, USA.

Padron, G.A.; Eagles, W.P.; Özcan-Taşkın, G. N.; McLeod, G.; Xie, L. (2008) Effect of particle properties on the break up of nanoparticle clusters using an in-line rotor-stator" Jrnl of Disp. Sci. and Tech., Vol. 29, Issue 4, p: 580- 586, doi: 10.1080/01932690701729327.

Quarch, K.; Durand, E.; Schilde, C.; Kwade, A.; Kind, M. (2010) "Mechanical fragmentation of precipitated silica aggregates" Chem Eng Res Des, (88) p: 1639- 1647

Sauter C.; Schuchmann H. P. (2007) "High pressure for dispersing and de-agglomerating nanoparticles in aqueous solutions" Chemical Engineering and Technology, Vol. 30, No.10; p: 1401- 1405.

Schilde, C., Nolte, H.; Arlt, C.; Kwade, A. (2011) "Effect of fluid-particle-interactions on dispersing nano-particles in epoxy resins using stirred-media-mills and three-roll-mills" Composites Science and Technology, 70, p:657-663. doi: 10.1016/j.compscitech.2009.12.021 Seekkuarachchi, I.; Tanaka, K.; Kumazawa, H. (2008) "Dispersion mechanism of nanoparticulate aggregates using a high-pressure wet-type jet mill” Chem. Eng. Sci., 63, p: 23412366.

Stenger, F.; Mende, S.; Schwedes, J.; Peukert, W. (2005) "Nanomilling in stirred media mills" Chem. Eng. Sci. (60) p: 4557- 4565 doi:10.1016/j.ces.2005.02.057 
Ulrich, G. D., and Riehl, J. W. (1982) "Aggregation and growth of sub-micron sized oxide particles in flames". Journal of Colloid And Interface Science, Vol.87(1), pp.257-265 (DOI: $10.1016 / 0021-9797(82) 90387-3)$

Utomo, A.T.; Baker, M.; Pacek, A. W. (2008) "Flow pattern, periodicity and energy dissipation in a batch rotor-stator" Chem. Eng. Res. Des., 86, p:1397- 1409 doi: 10.1016/j.cherd.2008.07012.

Xie, L.; Rielly; C. D.; \& Özcan-Taşkın, G. N. (2008) "Break-up of nanoparticle agglomerates by hydrodynamically limited processes" Journal of Dispersion Science and Technology, 29, 4, 573 - 579 (DOI: 10.1080/01932690701729211) 
